\title{
Jasmin Schnitzer
}

\section{Assoziationsbürger}

Der Status türkischer Staatsangehöriger im Vergleich zur Unionsbürgerschaft

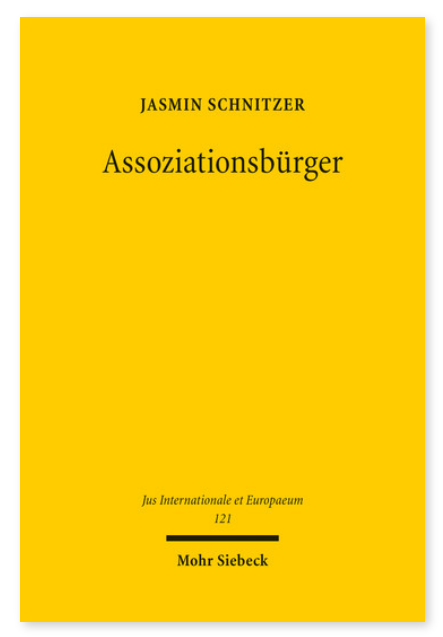

2016. XV, 313 Seiten. JusIntEu 121

ISBN 978-3-16-154663-1

DOI 10.1628/978-3-16-154663-1

eBook PDF 74,00€

ISBN 978-3-16-154662-4

fadengeheftete Broschur 74,00€
Das Assoziationsabkommen EWG/Türkei von 1963 begründet eine Assoziationsbürgerschaft türkischer Staatsangehöriger in der Europäischen Union, die als wirtschaftlich geprägte Wohnbürgerschaft zu klassifizieren ist. Die vergleichende Untersuchung mit der Unionsbürgerschaft zeigt, dass die Charakteristiken, welche die Unionsbürgerschaft als Status begründen, ebenso im türkisch-europäischen Assoziationsabkommen nachgewiesen werden können. Beide Status sind Ausdruck eines in zentralen Punkten übereinstimmenden bürgerschaftlichen Leitbildes, welches durch die Elemente der Gleichheit, Solidarität, Integration und Partizipation bestimmt wird. Die konzeptionelle Idee einer Bürgerschaft zeigt sich in den politischen Verhandlungen über die Fortentwicklung der Assoziation, prägt die Rechtsprechung des Europäischen Gerichtshofs und bestimmt das Verständnis der individuellen Rechte türkischer Staatsangehöriger.

Jasmin Schnitzer Geboren 1989; Studium der Rechtswissenschaft an der Goethe-Universität Frankfurt am Main; 2011 Erstes juristisches Staatsexamen; Wissenschaftliche Mitarbeiterin am Lehrstuhl für Öffentliches Recht und Europarecht an der Justus-Liebig-Universität Gießen; 2015 Promotion; seit 2015 Rechtsreferendarin am Landgericht Frankfurt am Main.

Jetzt bestellen:

https://mohrsiebeck.com/buch/assoziationsbuerger-9783161546631?no_cache=1

order@mohrsiebeck.com

Telefon: +49 (0)7071-923-17

Telefax: $+49(0) 7071-51104$ 